\title{
Genetic basis of persistent red blood cell microcytosis in the Chinese unexplained by phenotypical testing
}

\author{
Chi-Chiu So, ${ }^{1}$ Ada K Liu, ${ }^{2}$ Mandy H Tsang, ${ }^{2}$ Donna Y Ngai, ${ }^{2}$ Kin-Sang Leung, ${ }^{2}$ \\ Amy Y $\mathrm{Chan}^{3}$
}

'Department of Pathology, Faculty of Medicine, The University of Hong Kong, Hong Kong, Hong Kong ${ }^{2}$ Department of Pathology and Clinical Biochemistry, Queen Mary Hospital, Hong Kong, Hong Kong

${ }^{3}$ Department of Pathology, Queen Elizabeth Hospital, Hong Kong, Hong Kong

Correspondence to Dr Chi-Chiu So, Department of Pathology, Faculty of Medicine, The University of Hong Kong, Hong Kong, Hong Kong; scc@pathology.hku.hk

Received 19 July 2014 Revised 21 September 2014 Accepted 2 October 2014 Published Online First 28 October 2014

\section{ABSTRACT}

Aims Hypochromic microcytic anaemia is the hallmark phenotype of thalassaemia. Current phenotypical tests do not provide a diagnosis in a small proportion of patients with red blood cell microcytosis. We aim to evaluate the genetic basis of red cell microcytosis in these cases in our Chinese population.

Methods We identified from a large cohort of 1684 unselected requests for thalassaemia testing 23 Chinese subjects who had unexplained microcytosis after phenotypical iron and haemoglobin studies. In 18 of these subjects with available DNA, extensive genotypical analysis of the $\alpha$ and $\beta$ globin gene cluster was performed, including gap-PCR, multiplex amplificationrefractory mutation system, Sanger sequencing and multiplex ligation-dependent probe amplification. Results Occult single and double $\alpha$ globin gene (HBA 1, HBA2) deletions and $\alpha$ thalassaemic haemoglobinopathies (Haemoglobin Quong Sze, Haemoglobin Constant Spring) were the genetic basis for the microcytosis. Occult $\beta$ globin gene (HBB) mutations and $\delta$ globin gene $(H B D)$ abnormalities masking $\beta$ thalassaemia are not seen.

Conclusions A cost-effective genotyping approach for the detection of these occult globin gene mutations can be proposed. The identification of these mutations is important for making a diagnosis and for the provision of accurate genetic counselling. (This paper adds to our understanding of the genetic basis of red blood cell microcytosis in clinical practice, and it provides a costeffective approach for genotyping in diagnostic laboratories).

\section{INTRODUCTION}

A low mean corpuscular volume (MCV) is commonly used to screen clinical requests for thalassaemia studies after exclusion of iron deficiency. Phenotypical diagnosis of $\beta$ thalassaemia is typically made by measurement of the percentage of haemoglobin $(\mathrm{Hb}) \mathrm{A}_{2}$ by high performance liquid chromatography (HPLC) or capillary electrophoresis. In Southern Chinese and South-East Asian (SEA) populations where large deletions involving both $\alpha$ globin genes (HBA1, HBA2), such as the $\alpha$ SEA deletion, are the predominant causes of $\alpha$ thalassaemia, detection of $\mathrm{Hb} \mathrm{H}$ inclusion bodies in red blood cells by supravital staining remains as the mainstay test for phenotypical diagnosis of $\alpha$ thalassaemia. With technical experience it is very sensitive and specific in detecting $\alpha$-zero thalassaemia trait and probably also homozygous $\alpha$-plus thalassaemia trait. In a small proportion of subjects with red blood cell microcytosis, these phenotypical tests yield negative results. Globin gene mutations that may show such clinical presentation fall into several groups: (1) occult $\alpha$ thalassaemia due to single $H B A$ deletions and ultraunstable variants; (2) normal $\mathrm{Hb} \mathrm{A}_{2} \quad \beta$ thalassaemia due to mild $H B B$ mutations, large deletions of the $\beta$ globin gene cluster and mutations of the $\beta$-locus control region (LCR); (3) masked $\beta$ thalassaemia due to coexisting $\delta$ thalassaemia and variants; (4) amplification of $H B A$ leading to $\alpha$ and $\beta$ globin chain imbalance. In this study, we investigated the molecular basis of microcytosis in subjects who had a normal $\mathrm{Hb}$ phenotype. We aimed to document the occurrence and relative prevalence of various occult globin gene mutations and to establish a cost-effective laboratory approach for their detection.

\section{METHODS}

\section{Study subjects}

We screened all the 1684 records of thalassaemia studies performed in the Haematology Laboratory, Queen Mary Hospital, Hong Kong from January 2009 to December 2010. All subjects had microcytosis (MCV $<82 \mathrm{fL}$ ) except for $<1 \%$ of cases that were investigated for a suspected $\mathrm{Hb}$ variant. Subjects who were diagnosed as $\alpha$ and $\beta$ thalassaemia by phenotypical testing and subjects with iron deficiency as evidenced by a low serum iron level and/or a low transferrin saturation percentage were excluded. Subjects who had documented normalisation of MCV on follow-up complete blood count analysis were also excluded. Twenty-three subjects had persistent unexplained microcytosis. Peripheral blood film examination of red blood cells showed microcytosis only. None of these cases showed prominent basophilic stippling, including the three $\mathrm{Hb}$ Constant Spring (CS) cases. They had a normal $\mathrm{Hb}$ phenotype including an unremarkable HPLC chromatogram. Eighteen of them had archive specimens available for comprehensive genotypical analysis and were recruited into this study. Patient particulars and $\mathrm{Hb}$ phenotypes were summarised in table 1. All 18 subjects either had a normal $\mathrm{Hb}$ level or mild anaemia except for three cases, who had significant autoimmune haemolytic anaemia complicating their systemic lupus erythematosus (Case 4 and 14) and juvenile inflammatory arthritis (Case 17). These complicating diseases, however, could not explain the microcytosis.

\section{Standard $\alpha$ globin genotyping}

Frozen whole blood samples in EDTA were retrieved for molecular studies. Genomic DNA was extracted by the standard phenol/chloroform method. Single $H B A$ deletions of the $3.7 \mathrm{~kb}$ and $4.2 \mathrm{~kb}$ type and $\alpha$ SEA deletion were screened by a 
Table 1 Personal particulars, phenotype and globin genotype of 18 subjects with phenotypically unexplained microcytosis

\begin{tabular}{|c|c|c|c|c|c|c|c|c|c|c|c|c|c|c|c|}
\hline Sample number & Sex/Age & $\operatorname{RBC}\left(\times 10^{12} / L\right)$ & $H b(g / d L)$ & MCV (fL) & $\mathrm{MCH}(\mathrm{pg})$ & $\mathrm{Hb} \mathrm{A}(\%)$ & Hb F (\%) & $\mathrm{Hb} \mathrm{H}$ granules & $\alpha$ gap-PCR & $\alpha$ ARMS & $\alpha$ sequencing & $\alpha$ MLPA & $\beta$ sequencing & B MLPA & $\delta$ sequencing \\
\hline 1 & $F / 28$ & 4.51 & 12.0 & 79.6 & 26.6 & 3.2 & 0.7 & Neg & 4.2 Hetero & Neg & ND & ND & N & ND & $\mathrm{N}$ \\
\hline 2 & $\mathrm{M} / 12$ & 5.28 & 13.0 & 73.9 & 24.6 & 2.7 & 0.3 & $\mathrm{Neg}$ & Neg & $\mathrm{Hb} \mathrm{CS}$ & ND & ND & N & ND & $\mathrm{N}$ \\
\hline 3 & $F / 39$ & 4.89 & 12.0 & 73.1 & 24.5 & 3.0 & 0.3 & Neg & Neg & $\mathrm{Hb} \mathrm{QS}$ & ND & ND & N & ND & $\mathrm{N}$ \\
\hline 4 & $F / 44$ & 2.99 & 7.1 & 72.6 & 23.7 & 2.7 & 0.5 & $\mathrm{Neg}$ & SEA Hetero & $\mathrm{Neg}$ & ND & ND & N & ND & $\mathrm{N}$ \\
\hline 5 & $F / 42$ & 5.09 & 12.0 & 70.9 & 23.6 & 2.5 & 0.4 & $\mathrm{Neg}$ & $\mathrm{Neg}$ & $\mathrm{Hb} \mathrm{QS}$ & ND & ND & N & ND & $\mathrm{N}$ \\
\hline 6 & $\mathrm{M} / 12$ & 4.81 & 11.7 & 73.1 & 24.3 & 2.7 & 0.3 & Neg & Neg & Neg & $\mathrm{N}$ & Neg & N & Neg & $\mathrm{N}$ \\
\hline 7 & $F / 44$ & 5.10 & 13.1 & 77.8 & 25.6 & 3.0 & 0.5 & Neg & Neg & $\mathrm{Hb} \mathrm{QS}$ & ND & ND & N & ND & $\mathrm{N}$ \\
\hline 8 & $F / 20$ & 4.56 & 11.7 & 78.7 & 25.7 & 2.7 & 0.2 & $\mathrm{Neg}$ & Neg & Neg & $\mathrm{N}$ & Neg & N & Neg & $\mathrm{N}$ \\
\hline 9 & $\mathrm{M} / 23$ & 5.49 & 14.5 & 78.1 & 26.5 & 2.6 & 0.2 & $\mathrm{Neg}$ & Neg & $\mathrm{Hb} \mathrm{CS}$ & ND & ND & N & ND & $\mathrm{N}$ \\
\hline 10 & $F / 38$ & 5.00 & 13.2 & 78.7 & 26.4 & 2.8 & 0.3 & $\mathrm{Neg}$ & 3.7 Hetero & $\mathrm{Neg}$ & ND & ND & N & ND & $\mathrm{N}$ \\
\hline 11 & $F / 82$ & 4.15 & 10.5 & 78.8 & 25.2 & 2.3 & 0.5 & $\mathrm{Neg}$ & SEA Hetero & Neg & ND & ND & N & ND & $\mathrm{N}$ \\
\hline 12 & $\mathrm{M} / 81$ & 5.26 & 13.2 & 79.3 & 25.1 & 3.4 & 0.2 & $\mathrm{Neg}$ & Neg & $\mathrm{Hb} \mathrm{QS}$ & ND & ND & N & ND & $\mathrm{N}$ \\
\hline 13 & $F / 51$ & 4.48 & 10.3 & 72.2 & 23.1 & 2.2 & 0.1 & $\mathrm{Neg}$ & 3.7 Hetero & Neg & ND & ND & N & ND & $\mathrm{N}$ \\
\hline 14 & $\mathrm{M} / 17$ & 4.60 & 9.8 & 67.6 & 21.3 & 2.0 & 0.1 & Neg & 4.2 Hetero & Neg & ND & ND & N & ND & $\mathrm{N}$ \\
\hline 15 & $\mathrm{M} / 13$ & 4.91 & 12.7 & 77.0 & 25.9 & 2.6 & 0.5 & $\mathrm{Neg}$ & Neg & $\mathrm{Hb} \mathrm{CS}$ & ND & ND & N & ND & $\mathrm{N}$ \\
\hline 16 & $\mathrm{M} / 8$ & 5.56 & 12.8 & 70.5 & 23.0 & 2.9 & 0.3 & $\mathrm{Neg}$ & Neg & $\mathrm{Hb} \mathrm{QS}$ & ND & ND & N & ND & $\mathrm{N}$ \\
\hline 17 & $F / 4$ & 3.83 & 8.3 & 73.1 & 21.6 & 2.9 & 3.1 & $\mathrm{Neg}$ & Neg & Neg & $N$ & Neg & N & $\mathrm{Neg}$ & $\mathrm{N}$ \\
\hline 18 & $\mathrm{M} / 22$ & 5.22 & 13.4 & 77.7 & 25.6 & 2.9 & 0.3 & $\mathrm{Neg}$ & 4.2 Hetero & $\mathrm{Neg}$ & ND & ND & N & ND & $\mathrm{N}$ \\
\hline
\end{tabular}

3.7, $\alpha 3.7 \mathrm{~kb}$ deletion; $4.2, \alpha 4.2 \mathrm{~kb}$ deletion.

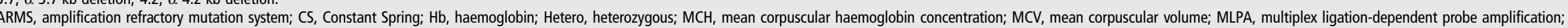
N, normal; ND, not done; Neg, negative; QS, Quong Sze; RBC, red blood cell count; SEA, $\alpha$ South-East Asian. 
multiplex $\alpha$ gap-PCR system. Selected $\alpha$ thalassaemic structural variants including $\mathrm{Hb}$ Quong Sze (QS), Hb CS and codon 30 deletion were screened by amplification refractory mutation system. Samples negative in both tests were subjected to automated Sanger sequencing of $H B A 1$ and $H B A 2$. All three tests were performed as previously described. ${ }^{1}$

\section{Standard $\beta$ and $\delta$ globin genotyping}

Point mutations causing $\beta$ and $\delta$ thalassaemia and structural variants were detected by automated Sanger sequencing of $H B B$ and $H B D$. Procedures for both genes were the same except for the specific primers used ( $\beta$ PCR primers: forward (833) 5'- TCCTAAGCCAGTGCCAGAAG-3'; reverse (834) 5'-GACCTCCCACATTCCCTTTT- $3^{\prime}$; $\delta$ PCR primers: forward (BE2) 5'-AAGTTAAGGGAATAGTGGAATGAAG-3'; reverse (BE9) 5'-CCCATTAATGCCTTGTACGG-3'). Genomic DNA samples were amplified by an ABI 9700 thermal cycler (Applied Biosystems, Foster City, California, USA) using the following cycling parameters: initial denaturation at $94^{\circ} \mathrm{C}$ for $5 \mathrm{~min}$, followed by 35 cycles of $94^{\circ} \mathrm{C}$ denaturing for $40 \mathrm{~s}, 57^{\circ} \mathrm{C}$ annealing for $40 \mathrm{~s}$, and $72^{\circ} \mathrm{C}$ extension for $3 \mathrm{~min}$. The presequencing cycle programme was $37^{\circ} \mathrm{C}$ for $30 \mathrm{~min}, 80^{\circ} \mathrm{C}$ for $15 \mathrm{~min}$. Sequencing primers for $H B D$ were the same as the PCR primers. For $H B B$ sequencing, apart from the forward (833) and reverse (834) primers, an additional forward primer (CA) 5'-CAATGTATCATGCCTCTTTGCACC-3' was also used to sequence the exon 3 and the $3^{\prime}$ untranslated region. The sequencing cycle was started with initial denaturation at $96^{\circ} \mathrm{C}$ for $10 \mathrm{~min}$, followed by 24 cycles of $96^{\circ} \mathrm{C}$ denaturing for $10 \mathrm{~s}$, $50^{\circ} \mathrm{C}$ annealing for $5 \mathrm{~s}$ and $60^{\circ} \mathrm{C}$ extension for $4 \mathrm{~min}$. Sequences were read by an ABI 3130XL sequencer (Applied Biosystems).

\section{Detection of amplifications and uncommon deletions in $\alpha$ and $\beta$ globin gene cluster}

Multiplex ligation-dependent probe amplification (MLPA) was employed in selected cases to screen for gene dosage changes, and deletions disrupting the upstream regulatory region HS-40 and $\beta$-LCR in the $\alpha$ and $\beta$ globin gene clusters, respectively. Probes and reaction mixture for ligation and PCR were purchased from MRC-Holland (SALSA MLPA kit P102 HBB and P140-B3 HBA, MRC-Holland, Amsterdam, the Netherlands). Testing and data analysis procedures were done as previously described. $^{2}$

\section{RESULTS}

A summary of the globin genotyping results is shown in table 1 . Of the 18 subjects tested, 15 (83\%) showed an $\alpha$ globin gene cluster mutation, with seven samples $(39 \%)$ of the deletional types (two cases of SEA type, two cases of $3.7 \mathrm{~kb}$ and three cases of $4.2 \mathrm{~kb}$ deletion) and eight samples (44\%) of the nondeletional types (three cases of $\mathrm{Hb} \mathrm{CS}$, five cases of $\mathrm{Hb} \mathrm{QS}$ ). The remaining three samples (17\%) showed normal molecular findings, with no evidence of point mutation in $\alpha$ and $\beta$ globin genes or amplification or deletion of the $\alpha$ and $\beta$ globin gene clusters. None of the 18 samples harboured $\beta$ or $\delta$ globin gene mutations as assessed by Sanger sequencing of the promoter, all exons and the $3^{\prime}$ untranslated region.

\section{DISCUSSION}

It is well recognised that single $H B A$ deletions and certain $\alpha$ thalassaemic variants such as $\mathrm{Hb}$ CS may present with a normal MCV and thus be missed by most thalassaemia screening programmes that are based on detection of microcytosis. ${ }^{3}$ Even when these mutations present with a low MCV, they are not effectively identified by routine phenotypical $\mathrm{Hb}$ studies. Supravital staining is notoriously insensitive in picking up single $H B A$ deletions, $\mathrm{Hb} C S$ and $\mathrm{Hb}$ QS because of the modest chain imbalance compared with double $H B A$ deletions such as the $\alpha$ SEA deletion. ${ }^{4}$ An immunochromatographic strip test which detects $\mathrm{Hb}$ Bart has improved detection rate for single $H B A$ deletions but its sensitivity is still only $83 \% .{ }^{5} \mathrm{~A}$ small amount of $\mathrm{Hb}$ CS may be evident in HPLC, capillary electrophoresis and alkaline $\mathrm{Hb}$ electrophoresis but the detection is unreliable. The ultraunstable $\mathrm{Hb}$ QS chain cannot be detected by routine methods at all. These occult HBA mutations can result in thalassaemic syndromes with significant morbidities when they occur in a homozygous state or in compound heterozygosity with other HBA mutations. These include deletional and nondeletional $\mathrm{Hb} \mathrm{H}$ disease which can present as $\mathrm{Hb} \mathrm{H}$ hydrops foetalis in extreme cases. ${ }^{6}{ }^{7}$ The same consideration also applies to masked $H B B$ mutations. Normal $\mathrm{Hb} \mathrm{A}_{2} \beta$ thalassaemia may be due to mild mutations in the $5^{\prime}$ untranslated region of $H B B$ that have no clinical significance. However, severe $\beta^{0}$ mutations can also be masked phenotypically by coexisting $\delta$ thalassaemic mutations in cis, a large deletion involving all the genes in the $\beta$ globin gene cluster or a deletion of the $\beta$-LCR. Genotypical analysis is necessary to effectively diagnose all these masked $\alpha$ and $\beta$ and thalassaemia mutations.

Our study results show that persistent microcytosis unexplained by phenotypical testing is an uncommon finding in clinical practice. Among 18 such cases in this study, $\alpha$ thalassaemic mutations accounted for all 15 cases of masked globin gene mutations detected. None of the 18 cases harbour any $H B D$ or $H B B$ mutations. Of note, two cases with $\alpha$ SEA deletion did not have detectable $\mathrm{Hb} \mathrm{H}$ granules. $\alpha$ globin genotyping was not routinely performed for cases already diagnosed by phenotypical testing to allow for direct calculation of diagnostic sensitivity of supravital staining in this study. However, from a previous study on the local Chinese population with red blood cell microcytosis, which showed a prevalence of $54 \%$ of $\alpha$ SEA deletion, ${ }^{8}$ the sensitivity of supravital staining for $\alpha$ SEA deletion in our cohort is around $99 \%$. This is highly acceptable for clinical diagnostic use. However, this test is observer-dependent. Use of more sophisticated phenotypical testing methods is required to diagnose $\alpha^{0}$ thalassaemia if $100 \%$ sensitivity is aimed at. ${ }^{5}$

The detection of three cases of $\mathrm{Hb}$ CS without $H B A$ deletion in our patient group is an interesting finding. It has been proposed that oxidised $\mathrm{Hb}$ CS binds to red blood cell membrane. This leads to membrane damage and overhydration of red blood cells, and causes normalisation of MCV despite the otherwise thalassaemic property of this variant. ${ }^{9} \mathrm{~A}$ low $\mathrm{MCV}$ and mean corpuscular haemoglobin concentration associated with $\mathrm{Hb}$ CS is regarded as an indicator of coexisting single $H B A$ deletion. ${ }^{10}$ The finding of microcytosis in our three cases of isolated $\mathrm{Hb}$ CS, including one case with a very low mean corpuscular haemoglobin concentration of $24.6 \mathrm{pg}$ (Case 2), does not support this claim. Basophilic stippling, as reported previously in homozygous $\mathrm{Hb} \mathrm{CS},{ }^{11}$ is absent in our cases. This is likely due to the fact that our three cases are only heterozygous. Homozygous $\mathrm{Hb}$ CS almost always has a normal MCV due to significant membrane damage. ${ }^{11}$

The cause of persistent microcytosis in the remaining five cases is uncertain. Uncommon large deletions or amplification of the globin gene clusters or disruption of their $5^{\prime}$ regulatory regions were not detected. Whether these cases still represent thalassaemia due to trans-acting factors outside of the globin gene clusters can be further investigated by globin chain synthesis or quantitative reverse transcriptase-PCR to document 


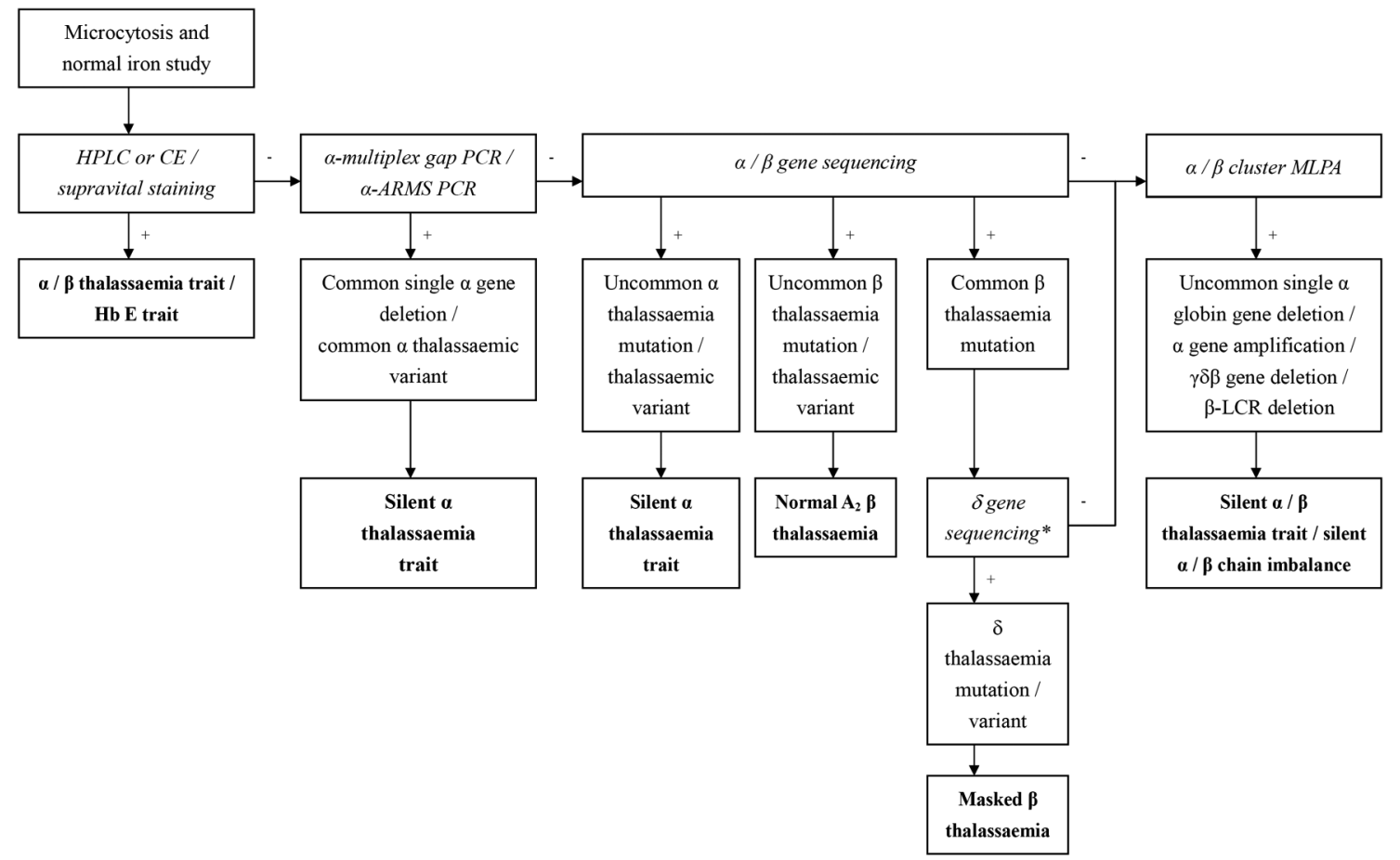

Figure 1 A proposed diagnostic algorithm for thalassaemia in Chinese patients with red blood cell microcytosis. ARMS, amplification refractory mutation system; CE, capillary electrophoresis; $\mathrm{Hb}$, haemoglobin; HPLC, high performance liquid chromatography; LCR, locus control region; MLPA, multiplex ligation-dependent probe amplification. ${ }^{*} \delta$ Gene sequencing indicated upfront if HPLC/CE shows an abnormal peak suspicious of a Hb $A_{2}$ variant.

relative globin gene expression. Unfortunately, fresh blood samples were not available for such analysis. Atypical microcytic anaemias due to rare inherited defects of iron metabolism present either with iron overload or deficiency and this should be detectable in the serum iron profile. There may also be associated neurological and endocrine disorders, which were not present in our subjects. ${ }^{12}$ Anaemia of chronic disease usually presents as normochromic normocytic anaemia but sometimes microcytosis can be seen as a result of iron-restricted erythropoiesis. This is reflected by low serum iron and transferrin levels and a raised ferritin level. Chronic lead poisoning is another acquired cause of microcytosis, where basophilic stippling is observed in red blood cells.

From our findings we propose a cost-effective genotyping approach to detect masked thalassaemic mutations for definitive diagnosis and genetic counselling in subjects with unexplained microcytosis (figure 1). Using simple $\alpha$ multiplex gap-PCR and amplification refractory mutation system, the underlying genetic cause for the microcytosis can be determined in most cases. More sophisticated and expensive molecular techniques such as Sanger sequencing and MLPA of the globin gene clusters are indicated only when the first line molecular tests yield negative results.

\section{Take home messages}

- Phenotypically unexplained red blood cell microcytosis is an uncommon clinical finding, yet a thorough search for masked thalassaemic mutations is important.

- Single HBA deletions and $\alpha$ thalassaemic structural variants account for most of these masked globin gene mutations.

- A cost-effective genotyping approach can be set up for the detection of such masked mutations.
Contributors C-CS designed the study, analysed the data, wrote the manuscript and is responsible for the overall content; AKL identified study samples, performed the experiments and reviewed the manuscript; MHT, DYN, K-SL and AYC performed the experiments and reviewed the manuscript.

Competing interests None.

Provenance and peer review Not commissioned; externally peer reviewed.

\section{REFERENCES}

1 Chan AY, So CC, Ma ES, et al. A laboratory strategy for genotyping haemoglobin $\mathrm{H}$ disease in the Chinese. J Clin Pathol 2007;60:931-4.

2 So CC, So AC, Chan AY, et al. Detection and characterisation of beta-globin gene cluster deletions in Chinese using multiplex ligation-dependent probe amplification. J Clin Pathol 2009;62:1107-11.

3 Chan LC, Ma SK, Chan AY, et al. Should we screen for globin gene mutations in blood samples with mean corpuscular volume (MCV) greater than $80 \mathrm{fL}$ in areas with a high prevalence of thalassaemia? J Clin Pathol 2001;54:317-20.

4 Lafferty JD, Barth DS, Sheridan BL, et al. A multicenter trial of the effectiveness of zeta-globin enzyme-linked immunosorbent assay and hemoglobin $\mathrm{H}$ inclusion body screening for the detection of alpha0-thalassemia trait. Am J Clin Pathol 2008;129:309-15.

5 Tayapiwatana C, Kuntaruk S, Tatu T, et al. Simple method for screening of alpha-thalassaemia 1 carriers. Int J Hematol 2009;89:559-67.

6 Charoenkwan P, Sirichotiyakul S, Chanprapaph P, et al. Anemia and hydrops in a fetus with homozygous hemoglobin Constant Spring. J Pediatr Hematol Oncol 2006;28:827-30.

7 Li DZ, Liao C, Li J, et al. Hemoglobin $\mathrm{H}$ hydrops fetalis syndrome resulting from the association of the --SEA deletion and the alpha ${ }^{\text {Quong Sze }}$ alpha mutation in a Chinese woman. Eur J Haematol 2005;75:259-61.

8 Lau YL, Chan LC, Chan YY, et al. Prevalence and genotypes of alpha- and beta-thalassemia carriers in Hong Kong-implications for population screening. N Engl J Med 1997;336:1298-301.

9 Schrier SL, Bunyaratvej A, Khuhapinant A, et al. The unusual pathobiology of hemoglobin constant spring red blood cells. Blood 1997;89:1762-9.

10 Uaprasert N, Rojnuckarin P, Settapiboon R, et al. Hematological characteristics and effective screening for compound heterozygosity for $\mathrm{Hb}$ constant spring and deletional $\alpha+$-thalassemia. Am J Hematol 2011;86:615-7.

11 Pootrakul P, Winichagoon P, Fucharoen S, et al. Homozygous haemoglobin Constant Spring: a need for revision of concept. Hum Genet 1981;59:250-5.

12 Camaschella C. How I manage patients with atypical microcytic anaemia. Br J Haematol 2013;160:12-24. 